\title{
The Quebec Task Force on \\ whiplash-associated disorders and the British Columbia Whiplash Initiative: A study of insurance industry initiatives.
}

\author{
Robert W Teasell MD FRCPC ${ }^{1}$, Harold Merskey DM FRCPC ${ }^{2}$
}

\begin{abstract}
RW Teasell, H Merskey.
The Quebec task force and the British Columbia Whiplash Initiative: A study of insurance industry initiatives.

Pain Res Manage 1999;4(3):141-149.

Two studies on whiplash-associated disorders that were generated by insurance companies were reviewed. The Quebec Task Force (QTF) report was comprised of a cohort study, a best evidence synthesis and consensus recommendations. The British Columbia Whiplash Initiative (BCWI) propagated the QTF recommendations.

The Quebec Task Force Cohort Study: This study was designed to determine retrospectively the natural history of whiplash injuries, however, recovery from whiplash injuries was determined by the discontinuation of payments and not by the resolution of symptoms. Patients complaining of 'recurrences', who comprised a substantial percentage of the total number of patients studied, were specifically excluded from the data set. When these patients were included in the data set, the percentage of patients who failed to recover (based on whether they were still receiving compensation) had risen from the reported $2.9 \%$ to as high as $12.4 \%$ after one year. It is impossible to draw valid conclusions about the natural history of whiplash injuries from this study because it did not study recovery from whiplash symptoms and excluded the majority of patients who were classified as 'recurrences' from the final study analysis.
\end{abstract}

The Quebec Task Force Best Evidence Synthesis Including Interventions: This analysis identified the paucity of conclusive research regarding treatments for whiplash. The paucity of conclusive research limited the number of conclusions that could be drawn.

The Quebec Task Force Consensus Recommendations: Despite a recognized lack of quality research, a consensus report that focused on therapeutic interventions was made. This consensus report is of concern because there was limited evidence to support the consensus, the classifications and recommendations were entirely arbitrary, the cohort data that the consensus panel relied upon to identify a natural history was seriously flawed, funding for the study was partisan, there was potential for abuse of guidelines, and there was a failure to deal with chronic

\section{whiplash injuries.}

The British Columbia Whiplash Initiative: This report, which was designed as a set of educational modules, relied heavily on the QTF, particularly the cohort study and the consensus recommendations. As a result, the report was based upon a flawed and overly optimistic picture of the natural history of whiplash disorders, and an arbitrary classification and management system. Both the QTF and the BCWI draw attention to the potential dangers of insurance industry initiatives designed to persuade medical and allied health professionals to accept viewpoints that appear overoptimistic and potentially self-serving.

Key Words: British Columbia Whiplash Initiative; Insurance; Quebec Task Force; Whiplash

\section{Le GTQ sur les troubles associés à l'entorse cervicale et l'Initiative de la \\ Colombie-Britannique sur l'entorse cervicale : une étude des initiatives de l'industrie des assurances sur l'histoire naturelle et la prise en charge de l'entorse cervicale}

\begin{abstract}
RÉSUMÉ : Deux études sur les troubles associés à l'entorse cervicale et réalisées par des compagnies d'assurances ont été passées en revue. Le rapport du Groupe de travail québécois (GTQ) comprenait une étude de cohorte, une synthèse des meilleures données disponibles et des recommandations consensuelles. L'Initiative de la Colombie-Britannique sur l'entorse cervicale a diffusé les recommandations du GTQ. L'étude de cohorte du Groupe de travail québécois. Cette étude était conçue pour déterminer de façon rétrospective l'histoire naturelle de l'entorse cervicale ; cependant, la guérison après une entorse cervi-
\end{abstract} voir page suivante

\footnotetext{
${ }^{1}$ Department of Physical Medicine and Rehabilitation, ${ }^{2}$ Department of Psychiatry, University of Western Ontario, London Health Sciences Centre, London, Ontario

Correspondence and reprints: Dr Robert Teasell, London Health Sciences Centre, 339 Windermere Road, London, Ontario N6A 5 A5.

Telephone 519-663-3235, fax 519-663-2941, e-mail robert.teasell@lhsc.on.ca

Received for publication July 2, 1999. Accepted for publication August 6, 1999
} 
cale a été déterminée sur un critère de cessation de l'indemnisation et non sur celui de la résolution des symptômes. Les patients se plaignant de « rechutes », qui constituaient un pourcentage important du nombre total des patients étudiés, étaient spécifiquement exclus du groupe de données. Quand ce groupe de patients était inclus dans les données, le pourcentage des non guéris (toujours indemnisés) après un an passait du 2,9\% rapporté à aussi haut que 12,4\%. Il est donc impossible de tirer des conclusions valables au sujet de l'histoire naturelle de l'entorse cervicale à partir de cette étude parce que cette dernière n'a pas étudié la guérison après des symptômes d'entorse cervicale et a exclu de l'analyse finale de l'étude la majorité des patients considérés comme des cas de « récidives.

La synthèse des meilleures donneés disponibles du Groupe de travail québécois incluant les interventions. Cette analyse a identifié la rareté des données probantes concernant le traitement des troubles associés à l'entorse cervicale. La rareté de telles données n'a donc pas permis de tirer toutes les conclusions nécessaires.

Les recommandations consensuelles du Groupe de travail québécois. Malgré la mauvaise qualité reconnue de cette recherche, un rapport consensuel se concentrant sur les interventions thérapeutiques a

Tn 1990, the Societe d'Assurance Automobile du Quebec (SAAQ), a provincial government no-fault insurance carrier located in Canada's second largest province, commissioned a group of clinicians, scientists and epidemiologists to conduct an exhaustive review of the scientific literature, and to make public policy recommendations regarding the prevention and treatment of whiplash and its associated disorders. The stated reasons for commissioning this study reflected a grievous concern with both the magnitude of the problem of whiplash-associated disorders (WADs) and the paucity of strategies to effectively address it. As stated in the report,

the frequency of the clinical entity labelled as whiplash is high, the residual disability of victims appears significant in magnitude, and the costs of care and indemnity are high and rising. There is considerable inconsistency about diagnostic criteria, indications for therapeutic intervention, rehabilitation and the appropriate role of clinicians at all phases of the syndrome. Little is known about primary prevention of the condition, and virtually nothing is known about tertiary prevention of serious disability (1).

The Quebec Task Force (1) adopted the following definition of whiplash:

an acceleration-deceleration mechanism of energy transfer to the neck. It may result from rear-end or side-impact motor vehicle collisions, but can also occur during driving or other mishaps. The impact may result in bony or soft tissue injuries (whiplash injuries), which in turn may lead to a variety of clinical manifestations

(Whiplash-Associated Disorders).

All the conclusions and recommendations drawn from the report were to be based on scientifically admissible studies when available. However, The Quebec Task Force Study on Whiplash-Associated Disorders concluded that the scientific evidence regarding whiplash was "sparse and generally of un- été rédigé. Ce rapport de consensus est inquiétant parce que les preuves appuyant le consensus étaient limitées, les classifications et les recommandations étaient totalement arbitraires, les données sur la cohorte dont s'est servi le comité d'experts pour déterminer l'histoire naturelle était sérieusement faussées, le financement pour cette étude était partisan, ces lignes directrices pouvaient être mal utilisées, et la question des troubles chroniques associés à l'entorse cervicale n'avait pas été abordée.

L'Initiative de la Colombie-Britannique sur l'entorse cervicale. Ce rapport, qui a été conçu comme un ensemble de modules d'enseignement, reposait lourdement sur le Groupe de travail québécois, en particulier sur l'étude de cohorte et les recommandations consensuelles. En conséquence, ce rapport était basé sur une image fausse et trop optimiste de l'histoire naturelle et sur une classification et un système de prise en charge arbitraires. Le GTQ et l'Initiative de la Colombie-Britannique sur l'entorse cervicale démontrent les dangers potentiels des études menées par l'industrie des assurances qui sont conçues pour convaincre les médecins et les autres professionnels de la santé d'accepter des points de vue qui semblent trop optimistes et intéressés.

acceptable quality", and they were forced to rely on consensus opinion for treatment recommendations; therefore, where adequate data did not exist, they conducted their own research or reached a consensus. This report remains the most ambitious and comprehensive review of the management of whiplash to date.

\section{The Quebec Task Force Cohort Study \\ THE QUEBEC TASK FORCE}

It is difficult to be definitive regarding the natural history of whiplash as there are no longitudinal studies (apart from those who have attended specialists' offices or who have sought attention in local emergency rooms). As a first step, the Quebec Task Force had to determine the natural history of whiplash injuries or an estimate thereof. As part of the Quebec Task Force Study (1), a cohort of 4757 subjects who submitted claims in 1987 to the Quebec provincial (single-payer) insurance plan were subsequently reviewed. A significant number were excluded from the study because of a lack of police collision reports (1743), leaving 3014 cases for review.

\section{Over-optimistic presentation}

The results of the Quebec Task Force Cohort Study have been presented as indicating a rate of recovery of $98.1 \%$ at one year or a 'failure' rate of 1.9\%. Both the Quebec Task Force (1) and Harder et al (2) published graphs of apparent recovery that have a striking asymptotic pattern on this basis. Freeman et al (3) pointed out that these favourable figures were suspect because patients with other injuries (eg, neck strain with back strain) were excluded from study. When those patients who had other injuries were included in the review, the proportion who were still absent from work or their usual activities after one year had risen to $2.9 \%$ (1).

The outcome variable of 'absence' previously mentioned "corresponded roughly to the amount of time taken off work by the whiplash subjects (if the subject was employed) or the length of time during which the whiplash subject could not 
carry out his or her usual activities (if the subject was a homemaker, retiree or otherwise unemployed)" (1). These intervals were determined in turn by the insurance company's decision that benefits were or were not payable. Problems in evaluating the figures and the impact of the Quebec Task Force definition of recovery are discussed below.

\section{Failure to describe or include recurrences properly}

Of the 3014 cases reviewed, 204 subjects were excluded from the data set because they had suffered a recurrence. Although it is not entirely clear from the paper what a 'recurrence' was, it states that recurrences, "defined as the recurrence of symptoms of collision-related injuries, were found to have occurred in 204, or $6.8 \%$ of the study subjects" (1). These 'recurrences' were not due to further collisions. It was also noted that "the rate of recurrence was higher with rear-end collisions and the presence of dependents at home". In addition, it was reported that, "of the 4757 subjects who had sustained a whiplash injury in Quebec in 1987, 303 individuals experienced at least one recurrence related to the injuries they sustained in the motor vehicle collision and cost the SAAQ \$2,876,964.37". It was later noted that:

since January 1, 1990, the duration of compensation has been limited to 2 years except in exceptional circumstances and a subject's file can be reopened to claim for further compensation if he/she experiences a recurrence or relapse of the injury. Any claimant who is dissatisfied with a decision rendered by the SAAQ may request that his/her file be re-examined (1).

It seems reasonable to assume from the quotations above that those patients who were deemed to have recovered but who continued to complain of symptoms were simply left out of the analysis. This left 2810 patients considered to be the study population. Cumulative 'recovery' rates were $22.1 \%$ within one week, $53 \%$ within four weeks, $64 \%$ within 60 days, $87 \%$ by six months and $97 \%$ by one year. However, if those 204 patients who suffered a 'recurrence', which presumably is an unresolved whiplash injury, are included in the analysis, the recovery rate at one year is substantially less and may be as low as $90.5 \%$ if it is assumed that all the recurrences were still symptomatic at one year. From clinical experience, the authors suspect that those individuals who were listed as recurrences were those who had improved at some point after injury but who gave up medications or returned to work and experienced an exacerbation of symptoms such that they were unable to continue to work. It is likely that they were experiencing symptoms that were never in full abeyance. It is necessary to include these 204 patients in the analysis to conduct an adequate evaluation of who is being compensated at one year. Because their symptoms would have recurred at various points, it is not unreasonable to assume that most of these patients were still having significant difficulties at one year. Taking only the 204 subjects who came from the group of 'uncomplicated whiplash' together with others who were known to still be receiving compensation at one year because of recurrences, we find that there were actually up to 285
(9.5\%) out of the 3014 subjects who received compensation at one year.

This figure may be too low for the Quebec Task Force cohort study because some data appear to be missing. There is potentially a group of 'recurrences'from the 'other injuries' category that were further excluded. The authors do not know how many of the 1259 individuals who had whiplash with other injuries were still symptomatic, sufficient enough to be labelled a 'recurrence'. The authors question whether there was a group of 'recurrences' or people who continued to have pain that was not included in the total of 3014 subjects. Table 5 of the Quebec Task Force document also has a puzzling feature: it is headed "Duration of absence and recurrence of symptoms by collision related factors" (1). The number under the heading 'Duration of absence' is given as a total of 2810 . The number under 'Recurrence of symptoms' is given as $n=1666$. This becomes clearer on page 6 , section 6 , where it states that the study cohort for the analysis of the 'rate of recurrence' had 1666 members, "since it excluded from the 3014 members the 1348 subjects with multiple injuries along with whiplash to ensure that recurrence was related only to whiplash injuries" (1). Table 6.3 of the Quebec Task Force document shows the number of subjects with combined whiplash and other injuries as 1259 (1). It is possible that the number of individuals with multiple (combined) injuries and recurrences is 1348 minus 1259, or 89 subjects. We conclude this with a degree of uncertainty, but it is the most reasonable way to explain the rather obscure arrangement of the data. If a further 89 subjects are added to the 285 subjects identified as receiving compensation so far, a figure of 374 (12.4\%) out of 3014 subjects is achieved. Therefore, the apparent chronicity of whiplash and complicated whiplash injuries at one year in Quebec as judged by the insurer's willingness to compensate these patients may be as high as $12.4 \%$ of all those individuals for whom the Quebec Task Force considered that there was sufficient data to conduct a proper follow-up. What becomes clear is that the rate of recovery for the cohort study is not nearly as optimistic as the $2.9 \%$ emphasized in the actual cohort study, even when allowing for their very liberal definition of 'recovery' (1). In order to resolve this issue, the Quebec Task Force should publish the percentage of whiplash claimants still symptomatic at 12 months including all cases from the population of 3014.

Recovery, as defined by the Quebec Task Force, appears to have been measured by a return to work or by the insurer's decision that individuals were fit to return to work and had no further need for compensation. The report states that the first outcome of interest was the duration of absence from usual activities for which some financial compensation was given. As noted above, the outcome variable was defined as:

the length of time, in days, between the date of the collision and the last date to which compensation to replace regular income was made by the SAAQ. In other words, this outcome corresponded roughly to the amount of time taken off work by the whiplash subject (if the subject was employed) or the length of time during which 
the whiplash subject could not carry out his or her usual activities (if the subject was a student, homemaker, retiree or unemployed) (1).

Because the duration of compensation is measured cumulatively and does not allow successive intervals of compensation to be distinguished in cases of 'recurrence', the study cohort for the first outcome excluded all subjects who suffered a ' $r$ ecurrence' as discussed above. In this cohort of patients compensated for whiplash injuries, the median time to recovery (end of disability compensation) was 31 days. It is not clear whether patients had actually returned to work (or usual activities) or were simply deemed able to do so by the insuring agency (SAAQ). Return to work is not an adequate criterion for recovery because it omits cases where individuals may return, but symptoms, even distressing symptoms, persist. It also includes individuals who may only be working part-time or in some type of employment shelter. In the end, it is not clear whether return to work was ever verified or whether it was assumed to be the same as the termination of relevant benefits. The authors suspect it was the latter criterion. Interestingly, only $19(0.4 \%)$ of the total 4757 whiplash claimants were assigned to a rehabilitation program by the SAAQ (1). It is noteworthy that the percentage of motor vehicle claims paid out for whiplash under the Quebec no-fault system appears to be only a fraction of that paid out by Canadian provinces with a tort system (1). Accordingly, the high recovery rates in the Quebec Task Force cohort likely reflect a higher threshold for allowing continued claims of disability or compensation, and all patients not receiving compensation are deemed to have recovered.

Compare this with prospective studies looking at consecutive patients seen in an emergency room, through family doctor referrals or in an acute orthopedic practice. Gargan and Bannister (4) studied 50 consecutive patients with soft tissue neck injuries attending an emergency room within five days of the accident. At three months, 15 patients were asymptomatic. Of these patients, 14 were still asymptomatic at two years. Thirty-five patients were symptomatic after three months; of these patients, 30 remained symptomatic after two years. After one year, 26 of the $50(52 \%)$ reported they had recovered completely, but only $19(38 \%)$ had recovered completely at two years. Radanov et al (5) studied 117 patients with a diagnosis of whiplash who were referred specifically for the study by primary care physicians. Initial assessment was conducted, on average, at seven days postinjury. Fifty-one (44\%), $36(31 \%)$ and 28 (24\%) of patients were symptomatic at three, six and 12 months, respectively. Hildingsson and Toolanen (6) prospectively studied 93 consecutive cases referred acutely to an orthopedic department because of a "non-contact injury to the cervical spine resulting from car accidents". At follow-up, an average of two years after the accident, $42 \%$ recovered completely, $15 \%$ had minor discomfort and $43 \%$ had discomfort sufficient enough to interfere with their capacity to work. Because these are regarded as three of the best prospective longitudinal studies, concerns have been raised about the applicability of the co- hort study, and in essence its validity, to actual whiplash recovery.

Because work readiness was the assumed end-point and few patients received rehabilitation, concerns were raised that the exceptional recovery rates reported simply reflected an unusually high 'threshold' for allowing continued claims of pain and disability. A recent study by Corey et al (7) on outcome in a functional restoration program suggests that discontinuation of insurance benefits is a very questionable indicator of 'recovery'. The authors followed a group of musculoskeletal pain patients who at three to six months postinjury were not working and were collecting Workers' Compensation Board benefits. At 18 months postinjury, $80 \%$ of these patients had been deemed 'recovered' because they were no longer receiving wage replacement benefits (8). However, in contrast with this $80 \%$ recovery rate, telephone follow-up at 18 months revealed that only $50 \%$ were either working (24\%) or looking for work (26\%). Although these findings cannot be directly extrapolated to the Quebec Task Force cohort, it is clear that defining recovery as discontinuance of insurance benefits significantly overestimates return to work and resolution of symptomatology in soft tissue injuries (1).

Unfortunately, interpretation of the data contained in the cohort study was difficult because the arrangement of the data itself was confusing. Table 6.3 contained in the Quebec Task Force report titled "Distribution of the duration of absence for members of the study cohort, excluding those with recurrence $(n=2810)$ " showed that of 2810 subjects 81 (2.9\%) had not returned to work after one year (1). This figure comprised 30 (1.9\%) of 1551 subjects with whiplash only, and 51 (4.1\%) of 1259 who had whiplash and other injuries. There was a cohort of 1956 patients who sustained a whiplash injury along with other injuries, and this is in apparent conflict with Table 6.3, which gives the number in that group as 1259 . The study states that $94(4.8 \%)$ of 1956 individuals were still being compensated 12 months after the collision, and they accounted for $36.1 \%$ of the total cost paid for by the SAAQ (1). Evaluation of where those figures came from and identifying which were the correct numbers was difficult. However, if we take the lower figure given in Table 6.3 of the document, it appears that, of the 2810 subjects (excluding recurrences), 81 (2.9\%) were being compensated at one year (1).

Selection bias in the cohort study was a problem. The study did not include patients with less than one week of time lost from work (the SAAQ only pays for time lost after one week has elapsed). The study did not include patients who did not seek compensation. Data were extrapolated to all individuals who had sustained whiplash injury in Quebec in 1987, not just those receiving compensation. Police reports are not as likely to be generated for more delayed symptoms.

\section{Summary of The Quebec Task Force Cohort Study}

The cohort study presents a remarkably optimistic picture of the recovery of whiplash injuries that has not been duplicated by careful studies in other jurisdictions. It does this by appar- 
ently separating out a significant number of patients with additional complications or 'recurrent' symptoms who obviously have not recovered and by defining 'recovery' as no longer being compensated by a 'no-fault' provincial insurance plan. This creates a misleading illusion of exceptional recovery rates and, in turn, forms much of the basis for the consensus treatment recommendations.

\section{Quebec Task Force best evidence synthesis/review of interventions}

Studies were accepted for the Quebec Task Force if they were deemed to be relevant and scientifically meritorious. Studies were rejected if the study was rated as either irrelevant or lacking in scientific merit. From November 1991 to April 1994, bibliographic information was compiled on 10,382 titles and abstracts, of which 1204 studies met the criteria for preliminary screening. Two hundred and ninety-four were selected for independent review by members of the committee. Only 62 studies (21\% of those reviewed) were accepted by the Task Force as both relevant and scientifically meritorious (1). Approximately $76 \%$ of the studies rejected were considered relevant. The Quebec Task Force did not include articles published before 1980 (unless deemed 'important' by members of the panel) or after 1993 .

A best evidence synthesis was put together to examine risk factors, diagnosis, interventions and prognostic factors. Specific interventions were the major part of this analysis. However, for almost every treatment, the Task Force found either no studies or a lack of independent studies (ie, the specific intervention was only included in multimodal studies or in conditions other than whiplash). Only facet joint injections, pulsed electromagnetic treatment and magnetic necklace were found to be of no benefit in acceptable clinical trials, and even these conclusions were based on only one study for each treatment (1).

Table 1 lists conclusions for each treatment; note the most common conclusion was "no studies". Therefore, based on a best evidence synthesis, for the vast majority of treatments, the authors cannot definitively conclude whether they are effective or ineffective, just that they have not been studied in isolation. However, because many of these interventions were incorporated as part of multi-interventional treatment, which proved to be of limited benefit, it would be surprising if they proved to be efficacious in isolation (9). The major message of the Quebec Task Force on WAD is that current scientific evidence on whiplash treatment is at worst deeply flawed and at best lacking. It concludes that the various modes of interventions must be investigated in a scientific manner. For most treatments of whiplash, proof of efficacy does not exist and the trend of evidence does not support their use.

\section{Quebec Task Force consensus guidelines}

After three years of deliberations by the Quebec Task Force, the evidence was found to be sparse and generally of unacceptable quality. The Quebec Task Force found 62 ad-

\begin{tabular}{|c|c|}
\hline Intervention & Study to establish benefit \\
\hline \multicolumn{2}{|l|}{ Immobilization } \\
\hline Soft collars & $\begin{array}{l}\text { Only studied in control groups. } \\
\text { May delay recovery by } \\
\text { promoting inactivity (three } \\
\text { studies) }\end{array}$ \\
\hline Rest & $\begin{array}{l}\text { No studies. Prolonged rest likely } \\
\text { detrimental to recovery }\end{array}$ \\
\hline Cervical pillows & No studies \\
\hline \multicolumn{2}{|l|}{ Activation } \\
\hline Manipulation & $\begin{array}{l}\text { No acceptable studies } \\
\text { establishing short term or } \\
\text { long term effectiveness }\end{array}$ \\
\hline Mobilization & $\begin{array}{l}\text { No studies. Likely beneficial } \\
\text { over short term. Long term } \\
\text { benefit not established }\end{array}$ \\
\hline Exercise & $\begin{array}{l}\text { Not independently studied. } \\
\text { As part of a "multimodal } \\
\text { intervention" may be } \\
\text { beneficial }\end{array}$ \\
\hline Traction & $\begin{array}{l}\text { Not independently studied. } \\
\text { No benefit demonstrated }\end{array}$ \\
\hline Postural advice & Not independently studied \\
\hline Spray and stretch & No studies \\
\hline \multicolumn{2}{|c|}{ Passive modalities and electrotherapies } \\
\hline TENS & No studies \\
\hline $\begin{array}{l}\text { Pulsed electromagnetic } \\
\text { treatment }\end{array}$ & No benefit (study) \\
\hline Electrical stimulation & No studies \\
\hline Ultrasound & No studies \\
\hline Laser, heat, ice, massage & No studies \\
\hline \multicolumn{2}{|l|}{ Surgery and injections } \\
\hline Surgery & No studies \\
\hline Nerve block & No studies \\
\hline Epidural injections & No studies \\
\hline Facet joint injection & No benefit (one study) \\
\hline $\mathrm{S} / \mathrm{C}$ sterile water injections & $\begin{array}{l}\text { Some benefit compared with } \\
\text { normal saline in unblinded } \\
\text { study }\end{array}$ \\
\hline $\begin{array}{r}\text { Pharmacological } \\
\text { interventions }\end{array}$ & No studies \\
\hline \multicolumn{2}{|l|}{ Other Intervention } \\
\hline Psychological treatments & No studies \\
\hline Prescribed function & Improved outcome in one study \\
\hline Acupuncture & No studies \\
\hline Magnetic necklace & No benefit (one study) \\
\hline
\end{tabular}

S/C Subcutaneous; TENS Transcutaneous electrical nerve stimulation

missible papers (1). Many of these were related to elements of whiplash other than therapy, and many of the therapy articles were negative studies. Positive articles were so sparse that even a meta-analysis of positive studies was not possible. Accordingly, for many aspects of its mandate, the Task Force was forced to invoke expert opinion to make recommendations in areas where the literature was weak.

The committee noted, "the systematic review of the original research literature yielded little scientifically rigorous 
information addressing the mandate to the Task Force by the SAAQ". The consensus recommendations were "based on the best evidence available, or where evidence was lacking, on the combined experience and judgement emerging from extended in-depth discussions of the Task Force members" (1). The danger of such consensus guidelines provided in the face of little scientific evidence is that they give the false impression of being built on a foundation of scientific truth or facts because they follow an excellent best evidence evaluation of interventions.

Further concerns are raised when one considers that the consensus guidelines were put into place with the flawed cohort data set as a presumed guide to the natural history of whiplash injuries. The resultant classification scheme WAD I-IV is arbitrary, with little or no supporting evidence apart from the overoptimistic cohort study. In addition, such a classification scheme presumes that one can determine the probable natural history based on the early physical examination. However, as acknowledged by the Quebec Task Force, the degree of agreement for examination of the cervical spine is generally very poor. The management schema for each of these classification groups is empirical, given the preceding section concluded that there was little in the way of acceptable evidence. Nevertheless, the classification system of WAD I-IV has been heavily promoted by the insurance industry in Quebec, Ontario, Saskatchewan and British Columbia, to name a few jurisdictions. Hence, whiplash injured patients have been saddled with a management schema based on arbitrarily chosen groupings, overoptimistic estimates of recovery, unreliable criteria and untested management strategies.

Even more worrisome was the fact that the government no-fault insurance carrier, hardly a disinterested party, funded the consensus development. Consensus was reached using a panel which, with two exceptions, had a relatively sparse or nonexistent publication record in the area of whiplash. Moreover, the guidelines did not address the issue of chronic whiplash. That is, treatment recommendations were for the first 12 weeks postinjury. Perhaps this is because the consensus panel was relying quite heavily on the cohort study, which gives a falsely optimistic picture of recovery. Accordingly, the apparent wholesale adoption of these guidelines by the insurance community is questionable at best and could be construed as particularly self-serving. The Task Force noted that they "put forward some controversial courses of action in the belief that public debate would be of value" (1). It was also stressed that these "recommendations reflect the consensus of the Task Force that the prognosis of WAD can be altered by optimum management" (1).

Consensus guidelines are only as good as the individuals providing the consensus guidelines, it is hoped without bias, and the evidence upon which the consensus guidelines are based. Because bias is a concern and the evidence upon which the consensus was formulated is considered sparse or misleading, the consensus guidelines must be viewed with scepticism. Some bias was declared by the Quebec Task Force: [t]he philosophy of the Task Force in evaluating treatment was one of prudence in the absence of evidence. We required that any therapeutic intervention should do more good than harm and that health care should not medicalize a condition or reinforce disability behaviour (1).

Based upon anecdotal experience, parts of the consensus guidelines appear to fit the evidence (eg, early activity) while others lack adequate proof (eg, multidisciplinary care). Moreover, they are often somewhat vague, which may be indicative of the lack of hard data. There is always the risk that such guidelines may be abused. As well, the issue of chronic whiplash is not dealt with apart from implying psychogenesis or factors other than the whiplash injury itself.

\section{Conclusions on The Quebec Task Force}

The Quebec Task Force is useful in that it highlights a paucity of good scientific evidence, provides an excellent review of some of the scientific evidence, sparse as it is, and provides consensus guidelines that are not unreasonable. Limitations include the fact that conclusions are drawn from a flawed and misleading cohort study, there is an implication that treatments are ineffective when no studies have been done, the consensus guidelines are admittedly only opinions and recommendations, and the guidelines do not deal with the issue of chronic whiplash pain and tends to imply psychogenesis. The Back Letter (10), in discussing the Quebec Task Force guidelines, noted that, "Like other guidelines, this report was a somewhat uncomfortable melding of 'scientific evidence'from flawed studies and 'consensus' findings by the panel in the absence of definitive scientific evidence".

\section{THE BRITISH COLUMBIA WHIPLASH INITIATIVE}

The British Columbia Whiplash Initiative (BCWI) reportedly arose from a symposium sponsored in Alberta in 1995 by the Physical Medicine Research Foundation (PMRF) (11). The PMRF is funded by the Provincial Insurance Corporation of British Columbia, a well-known American and Canadian insurance company, and by a private industrial organization (Woodbridge Industries, Mississauga, Ontario) about which little relevant information is known. For most of its existence, the PMRF has lacked prominent clinical scientists on its board or advisory committees, and until approximately 1997 had no Royal College of Physicians and Surgeons certified specialists in physical medicine among its known professional advisors. The PMRF concluded that the Quebec Task Force presented the best evidence-based synthesis of the literature to date. Funding for the BCWI came from the $\mathrm{PMRF}$ as an educational grant largely given by The Insurance Corporation of British Columbia (similar to the Quebec Task Force). The BCWI was dedicated to developing a multifaceted continuing educational program for physicians on the diagnosis, treatment and management of patients with WADs. The overall objective was to assist physicians with the diagnosis and treatment of patients with WAD using, where possible, evidence-based guidelines (11).

The BCWI attempted to be comprehensive but lacked the 
attempted rigor that characterized the Quebec Task Force, despite its obvious flaws. Apart from the sections on impact dynamics and chronic pain management, the BCWI relies very heavily on the Quebec Task Force, particularly the flawed cohort study, and the arbitrary and empirical consensus management guidelines. Given that the Quebec Task Force was five years old with serious flaws and limitations, one would have anticipated that the authors and research committee of the BCWI would have updated the research literature and recognized what conclusions can be validly draw from the Quebec Task Force. However, the authors of the BCWI failed to do either but rather liberally added poorly evidenced and biased opinions, which serve only to magnify the errors of the Quebec Task Force to the detriment of whiplash patients in British Columbia.

The BCWI is divided into several modules (1). Module 1 focused on the natural history and pathophysiology of whiplash injuries (11). Here there is a heavy reliance on the previously discussed Quebec Task Force cohort study. This module suggests, without providing corroborative evidence, that certain psychosocial factors contribute to prolonged recovery. "Pre-existing psychological problems and personality are widely considered to have a major influence on injury behavior" because it is "widely discussed in The Quebec Task Force" despite the fact that the Quebec Task Force provided little highlevel evidence in this regard. Critical studies are either missed or ignored. For instance, there is no discussion of the work of Bogduk and his colleagues in Australia who have spearheaded the most exciting advances in understanding of the underlying etiology of chronic whiplash injuries (12). The result is an implication that all whiplash injuries should recover quickly and should respond well to return to normal activities. Failure to do so is regarded as a consequence of psychosocial variables and not ongoing pathological changes. In other words, all whiplash injuries should get better and heal pain-free; if not, then vague 'psychosocial variables' are to blame.

Module 2 is on WAD diagnosis and management (11). This part of the BCWI again heavily depends on the Quebec Task Force, and where it deviates no supporting evidence is provided. The BCWI accepts the Quebec Task Force proposed clinical classification of WAD (WAD I-IV), which it states is "one of the most important contributions of the Task Force" despite the fact that it also admits the classification system has not been validated. On the basis of a rather liberal interpretation of the Quebec Task Force Cohort Study, it then attempts to provide natural history charts for which it offers no evidence. The result is prognostic predictions that are even more optimistic than those of the Quebec Task Force Cohort Study, even though the Quebec Task Force Cohort Study grossly overestimates the recovery rate of whiplash injuries by ignoring the recurrences and including only those select few who have not yet been cut off from compensation as not having recovered. The only acknowledgement for possible chronicity of whiplash injuries is "resolution may be delayed, sometimes lingering for months".
If symptoms are initially delayed, as is often the case with whiplash injuries, the BCWI recommends that they be classified as WAD I, for which "long term disability or impairment not expected". The BCWI states (without apparent evidence) that "pain severity itself, is a poor marker of injury severity" (11). However, Radanov et al (5) noted that it is one of the best markers of chronicity. The BCWI states that "constant pain, unrelenting, or worsening over time, may suggest psychological problems or symptom magnification or anxiety" and "chronicity may occur if the patient becomes very focused or concerned about their symptoms" (11). No reference or supporting evidence is provided.

The International Association for the Study of Pain definition of pain is wrongly quoted as "an unpleasant sensation or emotion associated with actual or potential tissue injury" (11). The correct definition is "an unpleasant sensory and emotional experience associated with actual or potential tissue damage, or described in terms of such damage" (13). The agreed upon definition was framed very carefully to provide for the recognition of pain whatever its cause. Turning an experience into an emotion as the BCWI does serves to support those who wish to treat pain as a psychiatric problem and, unfortunately, dismiss it accordingly. It is quite striking that a very carefully phrased definition is misquoted in three ways: "sensation or emotion" instead of "sensory and emotional experience"; "tissue injury" instead of "tissue damage"; and the omission of the key qualification concerning "described in terms of such damage".

These inaccuracies are followed by the statement that "a number of different pain syndromes have been identified with predictable clinical features" but " the causes are not clearly defined and the relationship to trauma is uncertain. Nonetheless, some of these syndromes appear to follow, or to be associated with, whiplash type events. These syndromes have at times been variously stated as being caused by whiplash" (11). Such statements represent attempts to separate the trauma from the pain syndromes despite the fact that such pain syndromes consistently follow whiplash trauma and have predictable clinical features.

The management model comes with a disclaimer that it does not consider causation and goes on to divide outcomes into physical (WAD I-IV) and nonphysical outcomes which, although not directly described as psychological, are to be treated with psychologically oriented treatment. The implication is that there are physical and psychological outcomes. However, what is truly unique is that myofascial pain syndrome, temporomandibular joint disorder, fibromyalgia, chronic pain syndrome, post-traumatic stress disorder and nonorganic symptom magnification are all included in the nonphysical outcomes (11). There are no supporting references for this unprecedented model.

Recommended strategies in the BCWI for early management of WAD still depend on the WAD I-IV classification. It is based on the Quebec Task Force, which is five years old and fails to incorporate any new research. The recommendation to 
avoid long term use of opiates does not reflect changing opinions regarding this issue (13). However, the treatment options are not unreasonable and the authors admit "evidence is inconclusive". They do state that "prolonged use of some of these may contribute to patient dependence and symptom chronicity" (11); we know of no systematic evidence to substantiate this statement.

The data on return to work for WAD II-III repeat the same error of depending on the Quebec Task Force cohort study data. As a result, the return to work percentages are inflated. Psychological factors of doubtful importance are again reiterated, while important factors such as more severe injury, the physical nature of the job, work autonomy and workplace adaptations are not mentioned. The implication is that patients who do not return to work do so because of greed or personal inadequacy. As well, the use of Canadian Medical Association guidelines quoted as supporting evidence fails to take into account the fact that appropriate work is often not available. Although return to work is to be encouraged by all physicians, research adapted from the chronic low back pain literature clearly indicates that the type of work and the ability of the workplace to adapt to the whiplash patient's limitations are powerful predictors of return to work.

Module 3 is devoted to chronic pain management (11). It contains numerous errors of fact and concept. Rather than go through all of them, two sections of bad teaching will be identified.

The section "Illness behaviour" introduces six categories (and four subcategories) of psychological issues. Listed under the category of conversion disorder are pain disorder, hypochondriasis, psychophysiological, psychosomatic pain and dysphoria. This is quite misleading because conversion disorder is ordinarily distinguished from somatoform disorders in those systems that use the term somatoform (for example, painful symptoms are not classed under conversion disorder by the Diagnostic and Statistical Manual of Mental Disorders [DSM]-IV]) pain disorder in DSM-IV is not a conversion disorder, nor are hypochondriasis, psychophysiological problems, psychosomatic problems or dysphoria.

The BCWI report holds the spread of symptoms to new areas, indicating psychological problems in individuals who have been injured, and, as mentioned earlier, there are strong reasons to believe that this is both naive and wrong. Secondary gain is simply described and followed by the statement that "low back pain studies suggest that job dissatisfaction was a high predictor of disability" (11), this is bolstered by reference to Spitzer et al (15), whose work is rarely cited to prove this and Bigos et al (16), who only dealt with acute back pain and showed that some patients with very short lasting acute back pain tended to come off work briefly if they did not like their employment. This related only to a minor proportion of the cases in the study (approximately 19\%) (17), and even the authors admitted it had only modest clinical significance. Moreover, this work did not deal with chronic pain or disability. In discussing post-traumatic depression, it is stated in the BCWI report that the patients in the Radanov et al (5) study were "seriously whiplashed". However, the fact these patients were whiplashed patients referred on average within one week of injury by family doctors for purpose of the study. There is no evidence these patients were seriously whiplashed, a term we suspect is used to explain why this study, which is regarded as one of the best natural history studies of whiplash, did not conform to the Quebec Task Force rates of recovery that form the basis of the BCWI.

Pain disorder is inadequately characterized by presenting one category of pain disorder (where psychological factors are judged to have an important role) and only representing those cases where both psychological and medical conditions coexist as 'some cases', as if they were of lesser importance, whereas DSM-IV does not state which is more important but merely describes two categories. Furthermore, the characterization is inaccurate in a way that might be contentious because the BCWI refers to "pain behaviour" in this discussion and the DSM-IV criteria cite pain and not pain behaviour, the word behaviour being introduced by the BCWI. As well, an important corollary statement in DSM-IV states that pain can also occur principally as a result of a general medical condition and is not then diagnosed as a psychiatric condition at all. Dysphoria, which is offered as another category in the list of pain disorder, hypochondriasis, psychophysiological or psychosomatic, and malingering or factitious disorder, but dysphoria is not described as a diagnosis in the sources from which 'pain' disorder and 'hypochondriasis' are drawn. Thus, there is a significant rearrangement of the concepts, putting together some that come from diagnostic systems and some that are descriptions of clinical phenomena, medical codes will follow this. The BCWI makes some remarkable statements about chronic pain syndrome (CPS). "CPS often fulfils all the DSM-IV criteria for somatization disorder, or pain disorder, part of the somatoform disorders". We have already seen the confusion which the BCWI has introduced to discussion of those conditions. Bonica (18) says the following about chronic pain disorder:

"In 1975 R.G. Black suggested that the term "chronic pain syndrome" be used for patients who suffer persistent, intractable pain complaints, "many of which are inappropriate to existing physical problems or illness, there is a history of multiple physician contacts and many non-productive diagnostic procedures, and there is excessive pre-occupation with the patient's complaint, both on the part of the patient, family and friends as well". At the time Black emphasized that the "syndrome of chronic pain" must not be confused with the chronic nociception that is obtained in patients with arthritis, thus suggesting that the term be limited to persistent pain caused by operant mechanisms. The introduction of this term has proven to be unfortunate because it has been inappropriately used by others and has caused much confusion. This confusion, together with the fact that there are many "chronic pain syndromes" indicate it should be discontinued (18).

The BCWI states also that "CPS is a condition of its own". The definition of CPS in the Chronic Pain Programs Guide- 
lines by the Department of National Health and Welfare Canada (19) is said to be similar to that of the American Medical Association (AMA) (20). The BCWI concludes, "CPS has the following characteristics." CPS is not referred to in the Health and Welfare booklet but chronic pain is. The authors can find no reference to the pattern that the BCWI attributes to the Health and Welfare Guidelines. The booklet states the following under Section 2.1:

Sometimes the cause of chronic pain is obscure. The disorder can occur in the absence of evidence of physical illness and, although unrecognized physical causes might exist in such cases they should not be implicated without good evidence of their presence. Psychological illness can be the cause of pain but also should only be used as an explanation if positive evidence is found to support such a diagnosis. Pain is often due to physical illness but is made worse or prolonged by independent psychological factors. (Here again, diagnosis depends upon supporting evidence). As well, chronic painful lesions might cause marked psychological changes (19). In 1990 and 1993, the AMA employed a description of chronic pain syndrome that has never been validated and that has not commended itself to other professional organizations (20).

\section{Summary of the BCWI}

Overall, the sections analyzed or annotated reflect a great deal of work, some knowledge of the literature and many statements that are not in dispute. However, there are also numerous flaws of interpretation, misleading presentations, factual errors and omissions. The report is presented as having been written in the spirit of evidence-based medicine but relies heavily on the Quebec Task Force. The BCWI employs concepts that have been widely rejected by workers in the field of chronic pain, emphasizes psychological factors with and without evidence for them, and downplays serious organic issues. The BCWI fails to review the large amount of literature on prognosis, and consistently suggests, without evidence, that certain psychosocial factors contribute to prolonged recovery. In addition, the BCWI continually implies that whiplash injuries all recover quickly and respond well to return to normal activities, and if they do not it is due to psychosocial variables. It is often repetitive, and the repetition tends to be in the direction of overstating alleged behavioural and psychological problems. This is the basis of management of whiplash in Module 2, which offers little evidence-based treatment and labels nonresponders as "psychological".

\section{CONCLUSIONS}

Whiplash injuries are a controversial area where there is a paucity of research and yet where substantial sums of money hinge on understanding the etiology, natural history and management of these injuries. Recent insurance-led initiatives in Canada have attempted to close this gap by systematically gathering and analyzing evidence, and providing guidelines on how to manage whiplash injuries. This information is then ag- gressively disseminated to clinicians with the expectation that it will modify clinicians' practices to the betterment of whiplash patients. However, this produces a potential conflict of interest. It is unlikely that any third party will fund guidelines that will have negative economic implications for the funding agency. Hence, a potential danger of bias enters into insurance initiatives for the development of treatment guidelines. The Quebec Task Force and BCWI illustrate some of the potential dangers of insurance-initiated guidelines designed to influence clinicians treating whiplash patients.

\section{REFERENCES}

1. Quebec Task Force on Whiplash-Associated Disorders Whiplash-Associated Disorders (WAD). Redefining "Whiplash" and Its Management. Societe de l'assurance automobile du Quebec. Quebec City, 1995.

2. Harder S, Veilleux M, Suissa S. The effect of socio-demographic and crash-related factors on the prognosis of whiplash. J Clin Epidemiol 1998;51:377-84.

3. Freeman MD, Croft AC, Rossignol AM. "Whiplash associated disorders: redefining whiplash and its management" by the Quebec Task Force. A critical evaluation. Spine 1998;23:1043-9.

4. Gargan MF, Bannister GC. The rate of recovery following whiplash injury. Eur Spine J 1994;3:162-4.

5. Radanov BP, Sturzenegger M, DeStefano G, Schnidrig A. Relationship between early somatic, radiological, cognitive and psychosocial findings and outcome during a one-year follow-up in 117 patients suffering from common whiplash. Br J Rheumatol 1994;33:442-8.

6. Hildingsson $\mathrm{C}$, Toolanen G. Outcome after soft tissue injury of the cervical spine. Acta Orthop Scand 1990;614:357-9.

7. Corey DT, Koepfler LE, Etlin D, Day IH. A limited functional restoration program for injured workers: a randomized trial. J Occup Rehab 1996;6:236-9.

8. Mitchell RI, Carmen GM. The functional restoration approach to the treatment of chronic pain in patients with soft tissue and back injuries. Spine 1994;19:633-42.

9. Teasell RW, Shapiro AP. Whiplash injuries: An update. Pain Res Manage 1998:3:81-90.

10. The Back Letter 1996;11:34.

11. BC Whiplash Initiative. Whiplash-Associated Disorders: A Comprehensive Syllabus. Vancouver, Physical Medicine Research Foundation, 1997.

12. Lord SM, Barnsley L,Wallis BJ, McDonald GJ, Bogduk N. Percutaneous radio-frequency neurotomy for chronic cervical zygapophyseal-joint pain. N Engl J Med 1996;335:1721-1726.

13. Merskey H, Bogduk N, eds. Classification of Chronic Pain. Descriptions of Chronic Pain Syndromes and Definition of Pain Terms, 2nd edn. Seattle: IASP Press, 1994.

14. American Psychiatric Association Diagnostic and Statistical Manual of Mental Disorders, 4th edn. Washington: Amerian Psychological Association, 1994.

15. Bigos SJ, Battie MC, Spengler DM, et al. A prospective study of work perceptions and psychological factors affecting the report of back injury. Spine 1991;16:1-6.

16. Spitzer WO, LeBlanc FF, Dupuis M. Scientific approach to the assessment and management of activity-related spinal disorders. Spine 1987;12:51-9.

17. Merskey H. Psychological medicine. In: Wall PD, Melzack R, eds. Textbook of Pain, 3rd edn. Edinburgh: Churchill Livingstone, 1994:903-20.

18. Bonica JJ. The Management of Pain, 2nd edn. Philadelphia: Lea \& Febiger, 1990:19-20.

19. National Health and Welfare Canada. Chronic Pain Programs Guidelines, 1990. Health and Welfare Canada, Ottawa.

20. American Medical Association. Guides to the Evaluation of Permanent Impairment, 4th edn. Chicago: American Medical Association, 1993. 


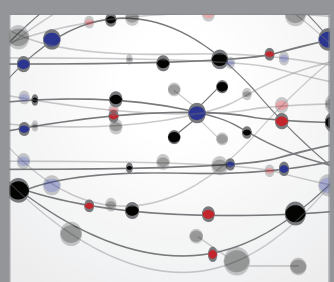

The Scientific World Journal
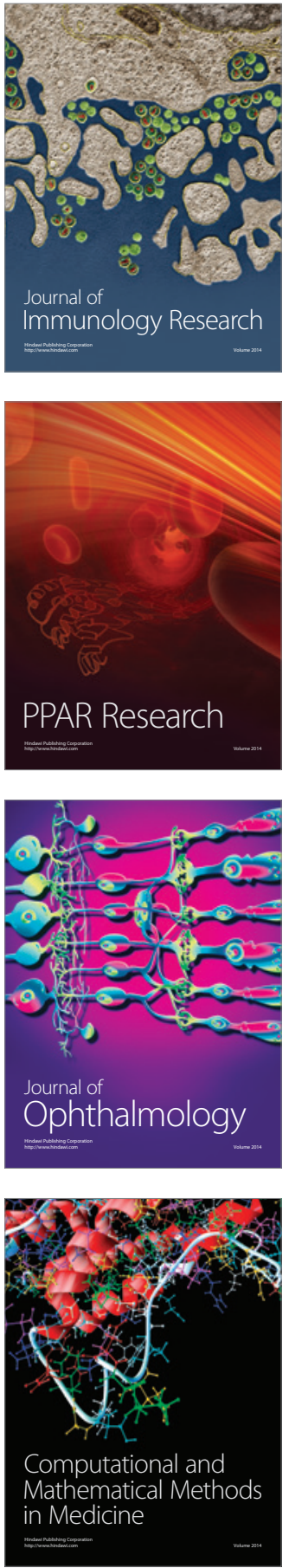

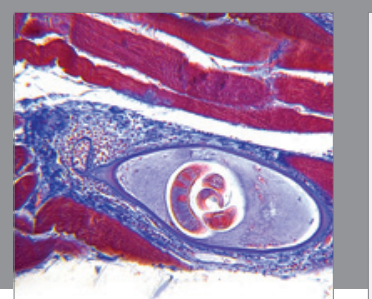

Gastroenterology Research and Practice

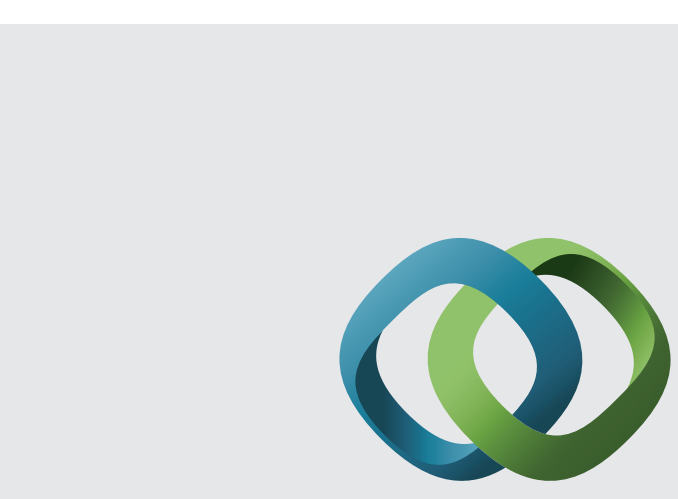

\section{Hindawi}

Submit your manuscripts at

http://www.hindawi.com
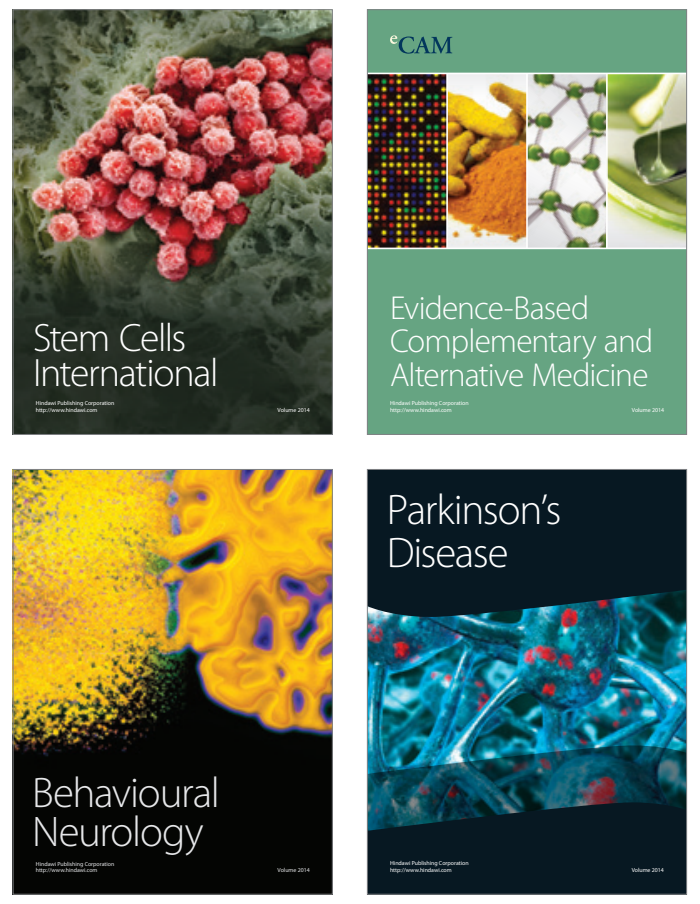
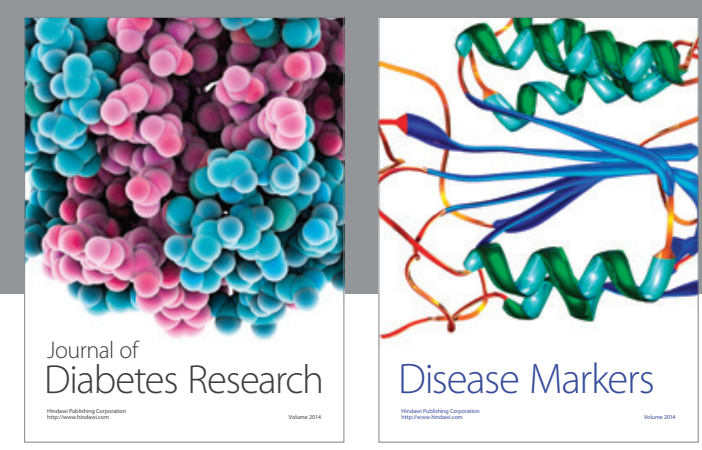

Disease Markers
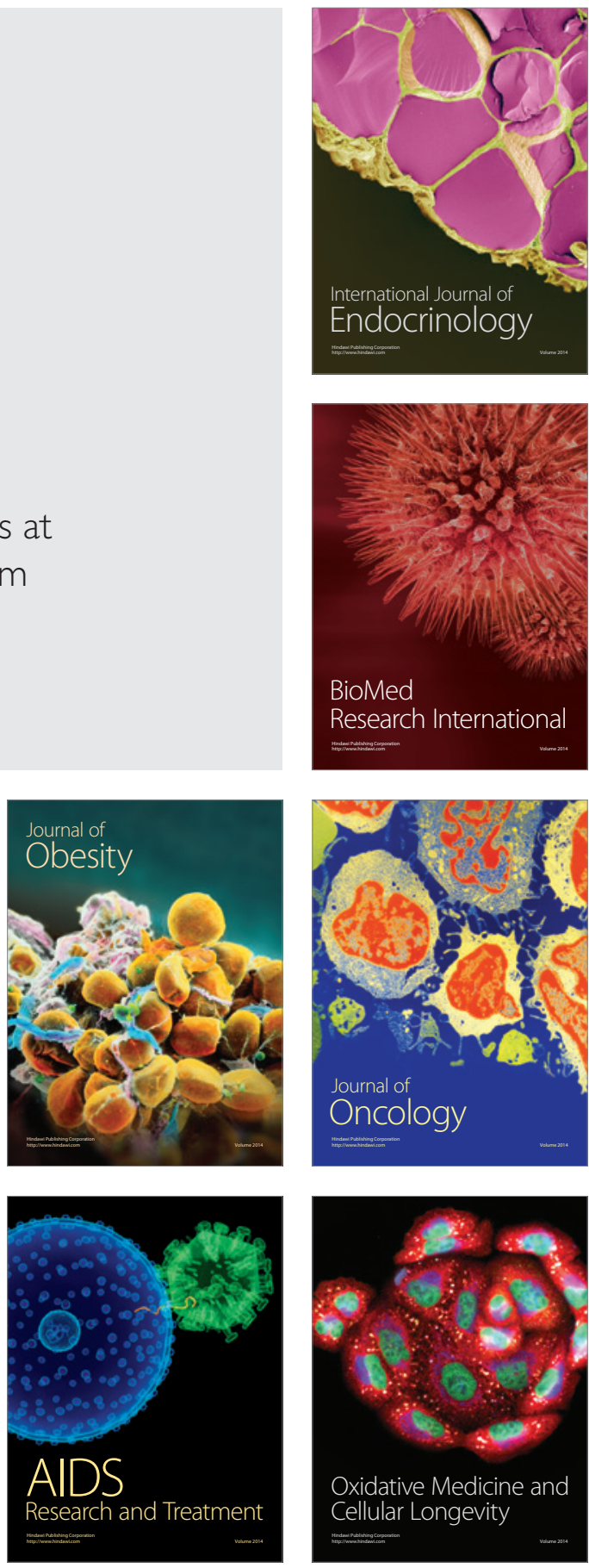